\title{
Predictors of sexual risk behaviour among adolescents from welfare institutions in Malaysia: a cross sectional study
}

\author{
Nik Daliana Nik Farid ${ }^{1,2^{*}}$, Sulaiman Che' Rus $^{3}$, Maznah Dahlui ${ }^{1,2}$, Nabilla Al-Sadat ${ }^{1,2}$, Norlaili Abdul Aziz ${ }^{1,2}$ \\ From International Research Symposium on Population Health 2013 \\ Kuala Lumpur, Malaysia. 18-22 November 2013
}

\begin{abstract}
Background: In welfare institutions, it is essential to address the health-related needs of adolescent populations who often engage in sexual activities. This study examines the association between individual and interpersonal factors concerning sexual risk behaviour (SRB) among adolescents in welfare institutions in Malaysia.

Methods: Data were derived from a cross-sectional study of 1082 adolescents in 22 welfare institutions located across Peninsular Malaysia in 2009. Using supervised self-administered questionnaires, adolescents were asked to assess their self-esteem and to complete questions on pubertal onset, substance use, family structure, family connectedness, parental monitoring, and peer pressure. SRB was measured through scoring of five items: sexual initiation, age of sexual debut, number of sexual partners, condom use, and sex with high-risk partners. Multivariate logistic regression analysis was used to examine the various predictors of sexual risk behaviour.

Results: The study showed that $55.1 \%(95 \% \mathrm{Cl}=52.0-58.2)$ of the total sample was observed to practice sexual risk behaviours. Smoking was the strongest predictor of SRB among male adolescents $(\mathrm{OR}=10.3,95 \% \mathrm{Cl}=1.25-83.9)$. Among females, high family connectedness $(\mathrm{OR}=3.13,95 \% \mathrm{Cl}=1.64-5.95)$ seemed to predict the behaviour.

Conclusion: There were clear gender differences in predicting SRB. Thus, a gender-specific sexual and reproductive health intervention for institutionalised adolescents is recommended.
\end{abstract}

\section{Background}

Sexual risk behaviour (SRB) includes premarital sex, early sexual initiation, unprotected sexual intercourse, sex with multiple partners, and unprotected sex with partners who are potential carriers of sexually transmitted infections (STIs) [1]. SRB is a major public health problem across the world, with well-documented risk factors [2]. However, the predictors of SRB among adolescents confined within welfare institutions are not well known. This gap in the literature is a cause for concern, given the linkages between SRB and adolescents' individual as well as interpersonal characteristics [3-6].

\footnotetext{
* Correspondence: daliana@ummc.edu.my

'Department of Social and Preventive Medicine, Faculty of Medicine,

University of Malaya, 50603, Kuala Lumpur, Malaysia

Full list of author information is available at the end of the article
}

In 2011, more than 60,000 adolescents in the United States were held in residential placement facilities after breaking the law [7]. In Malaysia, the 2010 census showed a five percent reduction from the previous year in the number of new adolescents held in welfare institutions: 1096 and 1319, respectively [8]. However, this figure excluded those confined within private welfare institutions [8]. These adolescents are medically underserved and often present with significant health concerns compared with their counterparts in the community [9]. A longitudinal study conducted among 800 juvenile detainees aged $10-18$ years in Chicago reported that more than $60 \%$ of adolescents had engaged in $\geq 10$ risk behaviours, including sexual risk behaviour, at the time of their baseline interview; nearly two thirds of them persisted in $\geq 10$ risk behaviours at the time of follow-up [10]. 
Adolescents in welfare institutions, including those in juvenile detention facilities, have been identified as a group that participates in sexual risk behaviours [10]. Some institutionalised adolescents may be at additional risk due to their history of substance use and lack of connectedness to family $[11,12]$. In addition, institutionalised adolescents have poor school attendance records and are unlikely to participate in general population surveys administered at schools. Various studies have found that these adolescents are likely to have sexual intercourse at early ages [13], have multiple sexual partners [14], and use condoms inconsistently $[15,16]$. These behaviours increase the risk for teenage pregnancy [17] and STIs [18,19] including human immunodeficiency virus (HIV) [20].

As with adults, adolescents detained in welfare institutions may be released at any point as they proceed through the justice system [21]. Thus, these institutions represent a unique opportunity for sexual and reproductive counselling and education, as well as screening and treatments to prevent related diseases such as STI sequelae and transmission.

This study examines the associations among individual factors (socio-demographic, self-esteem, pubertal onset, and substance use) and interpersonal factors (family structure, family connectedness, parental monitoring, and peer pressure) related to SRB among adolescents in the welfare institutions of Peninsular Malaysia. We provide recommendations for developing effective and tailored intervention programs that will improve adolescents' sexual and reproductive health within welfare institutions.

\section{Methods}

\section{Study design and participants}

We performed a cross-sectional study at 22 sites including children's homes, probation hostels, juvenile detention facilities, and a shelter for pregnant teenagers. These sites were located in the four regions (Northern, Central, Eastern and Southern) of Peninsular Malaysia. Study sites were selected systematically. Potential recruitment sites for adolescents were identified based on information available from the Social Welfare Department's website, along with recommendations made by the department's supervisory staff. A total of 28 sites were identified, but only 22 were approved by the department as study sites. Other institutions were excluded due to administrative issues that made data collection impossible.

All adolescents who resided in these institutions from October 2009 through June 2010 were eligible to participate in this study. Adolescents in welfare institutions are defined as persons who were younger than 18 years at the time of admission. Confinement in welfare institutions may result from a need for shelter or rehabilitation, or it may be due to abuse or unlawful activities [21]. The institutions are usually managed by a warden or principal and provide services for 10-100 individuals of a single gender category [21]. To be included in the cross-sectional study, adolescents had to meet the following criteria: 1) age ranging from 12-19 years; 2) single marital status; and 3) able to communicate in either written or spoken Malay or English language. Informed consent was obtained from the adolescents' present guardian (i.e., the Social Welfare Department of Malaysia). Additionally, participants provided verbal consent before the start of data collection.

Overall, 1082 eligible adolescents participated in the study. Participants were assured of confidentiality and the informed consent process was reviewed. The study was approved by the University Malaya Medical Centre Ethics committee.

\section{Study tools}

Data were collected through self-administered questionnaires. All measures used in this study have been previously evaluated and found to be compatible with Malaysian adolescents. The measures are discussed below.

\section{Demographic characteristics}

Demographic characteristics such as age, race/ethnicity, gender, and living situation were analysed. Participants selected their ethnicity from the following options: Malay, Chinese, Indian, or Other. Participants were asked if they were living with their mother and father, mother only, father only, mother/father and new partner, or others. The variable 'others' refers to relatives, foster family, or friends.

\section{Self-esteem}

The Rosenberg Self Esteem (RSE) scale was used to assess adolescents' levels of self-esteem. The RSE has previously been validated among Malaysian adolescents [22]. Ten self-esteem items e.g. "On the whole, I am satisfied with myself" and "At times, I think I am no good at all" were analysed, and the subscales were scored according to standard scoring methods [23-25]. Participants' self-esteem levels were determined based on the standard scoring. In the current study, the scale was reliable, with a correlation coefficient of 0.69 .

\section{Pubertal onset}

Puberty is marked by maturing of the genital organs, development of secondary sexual characteristics, and by the first occurrence of menstruation in the female [26]. Based on this definition, pubertal onset was assessed with an open-ended question: When did you first notice that your body was transforming, e.g. voice change in males and breast growth in females? The investigator developed this question and evaluated it prior to the actual study. The question was found to be reliable, with a Kappa value of 0.68 . Based on the period when puberty normally occurs, pubertal onset was then classified as early (7-8 years old), normal (9-13 years old), or late (14-19 years old) [26]. 


\section{Substance use}

Substance use was assessed with these questions: 1) Have you ever smoked a cigarette (at least one or two puffs) or tried any tobacco products such as cigars or shisha? (Kappa = 1); 2) In the past month, did you smoke? (Kappa = 1); 3) Have you ever drunk alcohol? (Kappa = 1); and 4) Have you ever used illicit drugs? (Kappa = 1). Participants who answered 'Yes' to the questions above were categorised accordingly as smokers, alcohol drinkers, and/ or illicit drug users.

\section{Family connectedness}

Family connectedness was assessed using measures adapted from the study 'Correlations between Family Meals and Psychosocial Well-being among Adolescents' [27]. Based on responses to the questions, 'How much do you feel you can talk to your caregiver about your problems?' and 'How much do you feel for your caregiver?' participants were categorised as experiencing low and high family connectedness. In the present study, the family connectedness items were reliable with a correlation coefficient of 0.61 .

\section{Parental monitoring}

Parental monitoring was assessed using The Parental Monitoring Assessment (Li et al. 2000; Small and Kerns 1993), which assesses an adolescent's perception of parental monitoring on a 5-point Likert scale from 1 (never) to 5 (always) [28,29]. Respondents were classified as having a low or high parental monitoring perception. In the Malaysian setting, after adaptation and evaluation, this scale was found to be reliable, with a Cronbach alpha of 0.84. Professor Steven Small from the University of Wisconsin granted permission to use this scale.

\section{Peer pressure}

The Peer Pressure Scale (PPS) was used to assess whether individuals experienced pressure from peers to do certain things. This nine-item scale was previously used in an adolescent population [30]. A correlation coefficient of 0.75 was established in the present study. The PPS subscales were scored according to standard scoring methods, and norms were used to determine whether participants had reached the appropriate cut-off scores for peer pressure.

\section{Sexual risk behaviour}

Adolescents who had experienced sexual intercourse were further questioned regarding their sexual risk behaviours: early sexual debut, unprotected sexual intercourse, multiple sexual partners, and sex with high-risk partners (e.g., intravenous drug users). SRB items were scored to determine whether participants had reached the appropriate cut-off scores for SRB [31,32].

\section{Data analysis}

Analyses were conducted using Predictive Analytics Software Version 17, (SPSS Inc, Chicago, IL, USA). Adolescents' socio-demographics were examined by gender. The bivariate relationships between individual and interpersonal factors and sexual risk behaviour were tested with chi-square tests. Significant associations of $p<0.05$ were combined and entered into logistic regression in a single full model. The full model was run separately for each gender to test the hypothesis that the predictors of SRB would be different for males and females. Variables that were not predictive at the $\mathrm{p}<0.05$ level were deleted from the final model. Seven subjects were excluded from the analysis because of missing data.

\section{Results}

Table 1 shows the distribution of socio-demographic characteristics of individuals in the study by gender. In terms of ethnicity, Malays were the dominant majority within the institutions $(86.9 \%)$ and there were more females than males: $55.4 \%$ and $44.6 \%$, respectively. The overall mean age of participants was 15.7 (range $=12-19$ ). Regardless of gender, more than $50 \%$ were living with both biological parents prior to their admission into the institutions. Most of them had attended school; $75.3 \%$ and $88.6 \%$ of male and female respondents, respectively, reported having received secondary education.

More than $50.0 \%(95 \% \mathrm{CI}=52.0-58.2)$ of the total sample was observed to practice sexual risk behaviours. The adolescents' reported sexual risk behaviour was examined by gender. There was a significant gender difference in terms of SRB. Female adolescents were more likely to engage in SRB compared to male adolescents $(\mathrm{p}<0.001)$ (Table 2).

Predictors of SRB among male adolescents included the use of substances such as tobacco, alcohol, and illicit drugs (Table 3). The findings indicated that tobacco use was the strongest factor $(\mathrm{OR}=10.3,95 \% \mathrm{CI}=1.22-1.80)$. Male adolescents who smoked tobacco were more likely to experience SRB compared to those who never smoked.

Among females, three variables contributed to SRB (Table 4). Only one variable was found to be similar to the outcome of logistic regression of SRB in males: alcohol use. Compared to males, additional factors found among females were family connectedness and self-esteem. With reference to family connectedness, female adolescents with high family connectedness were more likely to engage in SRB compared to those with low connectedness.

\section{Discussion}

The purpose of the study was to examine the associations between individual and interpersonal variables and sexual risk behaviour (SRB) among Malaysian adolescents residing in welfare institutions. The analysis showed that the majority of respondents were Malays, followed by Indians and Chinese. This ethnic distribution is almost the same as the ethnic distribution of adolescents detained for 
Table 1 Socio-demographic characteristics of adolescents

\begin{tabular}{|c|c|c|c|}
\hline Characteristics & $\begin{array}{c}\text { Overall }(\mathrm{N}=1,082) \\
\mathrm{N} \%\end{array}$ & $\begin{array}{c}\text { Male }(\mathrm{N}=483) \\
\mathrm{N} \%\end{array}$ & $\begin{array}{c}\text { Female }(\mathrm{N}=599) \\
\mathrm{N} \%\end{array}$ \\
\hline \multicolumn{4}{|l|}{ Ethnicity* } \\
\hline Malay & $939(86.9)$ & $410(84.9)$ & $529(88.5)$ \\
\hline Chinese & $38(3.5)$ & $25(5.2)$ & $13(2.2)$ \\
\hline Indian & $92(8.5)$ & $46(9.5)$ & $46(7.7)$ \\
\hline Others & $12(1.1)$ & $2(0.4)$ & $10(1.7)$ \\
\hline \multicolumn{4}{|l|}{ Age group (years) } \\
\hline $12-14$ & $258(23.8)$ & $116(24.0)$ & $142(23.7)$ \\
\hline $15-17$ & $699(64.6)$ & $288(59.6)$ & $411(68.6)$ \\
\hline $18-19$ & $125(11.6)$ & $79(16.4)$ & $46(7.7)$ \\
\hline \multicolumn{4}{|l|}{ Religion* } \\
\hline Islam & $974(90.1)$ & $429(88.8)$ & $545(91.1)$ \\
\hline Buddhism & $23(2.1)$ & $14(2.9)$ & $9(1.5)$ \\
\hline Christianity & $17(1.6)$ & $9(1.9)$ & $8(1.3)$ \\
\hline Hinduism & $59(5.5)$ & $26(5.4)$ & $33(5.5)$ \\
\hline Others & $4(0.4)$ & $2(0.4)$ & $2(0.3)$ \\
\hline No religion & $4(0.4)$ & $3(0.6)$ & $1(0.2)$ \\
\hline \multicolumn{4}{|l|}{ Family structure ${ }^{* *}$} \\
\hline $\begin{array}{l}\text { Mother \& } \\
\text { Father }\end{array}$ & $587(56.0)$ & $264(57.0)$ & $323(55.2)$ \\
\hline Mother only & $211(20.1)$ & $97(21.0)$ & $114(19.5)$ \\
\hline Father only & $55(5.2)$ & $18(3.9)$ & $37(6.3)$ \\
\hline Mother or father \& new partner & $13(1.2)$ & $3(0.6)$ & $10(1.7)$ \\
\hline Others & $182(17.4)$ & $81(17.5)$ & $101(17.3)$ \\
\hline \multicolumn{4}{|l|}{ Highest level of education ${ }^{* * *}$} \\
\hline $\begin{array}{l}\text { Primary } \\
\text { Education }\end{array}$ & $154(14.6)$ & $97(20.6)$ & $57(9.7)$ \\
\hline $\begin{array}{l}\text { Secondary } \\
\text { Education }\end{array}$ & $875(82.7)$ & $354(75.3)$ & $521(88.6)$ \\
\hline $\begin{array}{c}\text { Tertiary } \\
\text { Education }\end{array}$ & $10(0.9)$ & $7(1.5)$ & $3(0.5)$ \\
\hline
\end{tabular}

${ }^{*}$ Data is missing for 1 case. ${ }^{* *}$ Data is missing for 34 cases. Data is missing for 43 cases. Note: ${ }^{*}, * *$, ***percentages are calculated based on less than 1082 respondents due to missing data

Table 2 Reported sexual risk behaviour by gender

\begin{tabular}{|c|c|c|c|}
\hline Characteristics & $\begin{array}{c}\text { Overall }(\mathrm{N}=1082) \\
\mathrm{N} \%\end{array}$ & $\begin{array}{c}\text { Male }(\mathrm{N}=483) \\
\mathrm{N} \%\end{array}$ & $\begin{array}{c}\text { Female }(\mathrm{N}=599) \\
\mathrm{N} \%\end{array}$ \\
\hline \multicolumn{4}{|l|}{ Sexual debut } \\
\hline Early & $458(76.0)$ & $162(71.4)$ & $296(78.7)$ \\
\hline Late & $145(24.0)$ & $65(28.6)$ & $80(21.3)$ \\
\hline \multicolumn{4}{|c|}{ No. of lifetime sexual partners } \\
\hline One partner & $211(35.6)$ & $57(26.5)$ & $154(40.8)$ \\
\hline More than one & $381(64.4)$ & $158(73.5)$ & $223(59.2)$ \\
\hline \multicolumn{4}{|l|}{ Contraception use } \\
\hline Yes & $520(81.3)$ & $211(84.4)$ & $309(79.2)$ \\
\hline No & $120(18.8)$ & 39 (15.6) & $81(20.8)$ \\
\hline \multicolumn{4}{|c|}{ High-risk sexual partner } \\
\hline Yes & $187(30.2)$ & $89(36.9)$ & $98(25.9)$ \\
\hline No & $433(69.8)$ & $152(63.1)$ & $281(74.1)$ \\
\hline \multicolumn{4}{|l|}{ History of STI } \\
\hline Yes & $50(8.6)$ & $27(12.3)$ & $23(6.3)$ \\
\hline No & $534(91.4)$ & $193(87.7)$ & $341(93.7)$ \\
\hline
\end{tabular}

Note: Percentages are calculated based on number of respondents who completed the item on sexual initiation 
Table 3 Predictors of sexual risk behaviour in males

\begin{tabular}{lcccc}
\hline Variable & \multicolumn{4}{c}{ Multivariate modelling } \\
& B & OR & $\boldsymbol{P}$ & $\mathbf{9 5 \%} \mathbf{C l}$ \\
\hline $\begin{array}{l}\text { Tobacco use } \\
\text { Yes }\end{array}$ & 2.33 & 1.48 & $<0.0001$ & $\begin{array}{c}1.22-1.80 \\
\text { Ref }\end{array}$ \\
No & & 1.00 & & \\
Alcohol use & & & & $1.35-4.63$ \\
Yes & 0.92 & 2.50 & 0.004 & Ref \\
No & & 1.00 & & $1.28-4.39$ \\
Illicit drug use & & & & Ref \\
Yes & 0.86 & 2.37 & 0.006 & \\
No & & 1.00 & &
\end{tabular}

The sample size included in the logistic regression is less than the total sample of 483 due to missing data for some variables. Other variables entered: age, race, family structure, family connectedness, parental monitoring, peer pressure and pubertal onset. Hosmer-Lemeshow goodness of fit chi square $=3.53(\mathrm{df}=8), \mathrm{p}=0.90$.

Table 4 Predictors of sexual risk behaviour in females

\begin{tabular}{lcccc}
\hline Variable & \multicolumn{4}{c}{ Multivariate modelling } \\
& B & OR & $\boldsymbol{P}$ & $\mathbf{9 5 \%} \mathbf{C l}$ \\
\hline Alcohol use & & & & \\
Yes & 0.86 & 2.37 & 0.002 & $1.36-4.13$ \\
No & & 1.00 & & Ref \\
Family connectedness & & & & \\
High & 1.14 & 3.13 & 0.001 & $1.64-5.95$ \\
Low & & 1.00 & & Ref \\
Self-esteem & & & & $1.28-3.04$ \\
Low & 0.68 & 1.97 & 0.002 & Ref \\
High & & 1.00 & & \\
\hline
\end{tabular}

The sample size included in the logistic regression is less than the total sample of 599 due to missing data for some variables. Other variables entered: Age, race, tobacco use, illicit drug use, family structure, parental monitoring, peer pressure, pubertal onset and self-esteem. Hosmer-Lemeshow goodness of fit chi square $=8.18(\mathrm{df}=8), \mathrm{p}=0.42$.

juvenile misconduct at Henry Gurney Schools and the Prison Department of Malaysia [33]. The fact that the majority of the population within public welfare institutions is Malay may explain the higher number of Malays compared to other ethnic groups.

Most of the participants were female. This can be explained by the type of illegal acts committed and abuse experienced by the adolescents placed in the selected welfare institutions. While most offenses leading to arrest are committed by boys, girls account for the majority of adolescents taken into custody for running away, prostitution, uncontrolled behaviour and teenage pregnancy [34].

A rift among family members is a contributing factor to adverse adolescent outcomes [35]. However, in this study more than half of the adolescents were living with both biological parents. This finding corresponds to a report by the Prison Department of Malaysia that found that only $19.3 \%$ of juveniles serving prison sentences come from broken homes; the remaining $80.7 \%$ have intact families [33].

The use of substances such as cigarettes and illicit drugs was associated with SRB among males. These findings are consistent with previous studies that found that cigarette smoking and SRB are correlated with each other [36,37]. This could be due to conduct problems among institutionalised adolescents. A study of Greek adolescents found that conduct problems are associated with adolescent smoking [38]. Cigarette smoking, which led to conduct problems, in turn influenced adolescents to engage in SRB. Previous research has revealed that children with high rates of aggressive disruptive behaviours and attention problems at school entry are more likely to engage in problem behaviours in middle school; these behaviours are associated with early initiation of sexual activity [39].

Other studies have also found that adolescents who use illicit drugs may show a tendency to engage in SRB $[11,39]$. This association can be explained by high levels of sensation seeking [40]. High levels of sensation seeking have been directly linked to increased likelihood of drug use, which has been shown to influence SRB among boys [41-43]. Previous studies have shown that institutionalised adolescents are more likely to adopt high-risk behaviour such as substance use [9].

The current study identified alcohol use as a predictor of SRB for both male and female adolescents. This finding is consistent with previous studies that linked alcohol use to SRB $[44,45]$. To adolescents, alcohol is commonly used as a way of socialising with peers and coping with stress. Alcohol also facilitates contact with the opposite sex. This behaviour will eventually increase adolescents' involvement in SRB.

High family connectedness and low self-esteem were noteworthy factors of SRB among females. The current study found that female adolescents with high family connectedness were more likely to engage in SRB. This result contradicts findings from a previous review of studies of the general adolescent population. The review indicated that lower family connectedness was associated with sexual risk behaviour and higher connectedness was a protective factor [46]. The distinctive result found in the current study is probably due to mitigating circumstances. Although female adolescents who engaged in SRB might have had a perception of good family connectedness, parental monitoring might have been compromised. Adolescents' behaviour in front of their caregivers is often controlled, giving their parents the impression of obedience. This controlled behaviour fosters a better relationship between parent and child after institutionalisation.

Female adolescents with low self-esteem were more likely to engage in SRB. This finding is in contrast to a 
study that reported no significant association between self-esteem and SRB in female adolescents [47]. However, several studies have identified low self-esteem as a determinant of SRB $[48,49]$. Studies in a wide range of western countries have determined that adolescent females, on average, have lower self-esteem compared to males [50,51]. A previous study of self-esteem among Malaysian adolescents found that female adolescents are more likely than males to have low self-esteem [52]. In the current study, the adolescents' low self-esteem could be due to a lack of consistent communication with, support from, and encouragement by parents and other adult role models. Adolescents with low self-esteem are more likely to succumb to pressure from peers who practice SRB. Low self-esteem can make adolescents more vulnerable to SRB if they feel the need to experience SRB in order to fit in with their peers.

\section{Strengths and limitations}

The following limitations should be noted when interpreting some of the findings. Due to the cross-sectional nature of the study, the findings offer only a snapshot of the adolescents' SRB. Also, if one intends to look at causal relationships between the factors and sexual risk behaviour, temporal relationships between those factors should be examined carefully. Nevertheless, indication of associations was useful in generating hypotheses for future research. Even though the population sampled in this study was limited to adolescents from welfare institutions, this population could be said to represent at-risk adolescents in Malaysia.

\section{Recommendation}

The relationship between substance use and SRB illustrates the importance of addressing substance use when aiming to reduce adolescents' SRB. In order to change adolescents' attitudes towards substance use, individual as well as environmental interventions are required. It is necessary to develop interventions and programs for institutionalised adolescents that address substance use and its consequences for sexual and reproductive health. It is also important to involve the family in early religious and moral education (that is, education based on religion and culture). Another approach to be considered is a stricter policy prohibiting underage individuals from substance use in venues such as discos, concerts and bars. Targeted programs at these venues can promote behaviour that is more responsible and educate adolescents on the consequences of smoking cigarettes, drinking alcohol and using illicit drugs.

The link between family connectedness, self-esteem and SRB among female adolescents indicates the need for better individual and interpersonal prevention programs. Although female adolescents with SRB perceived high levels of family connectedness, other factors such as parental monitoring were probably lacking. Caregivers and teachers should be educated about and fully understand the risks associated with not monitoring adolescents. Parental monitoring can help protect adolescents from potential problems caused by the use of internet and social media outlets. Interventions and health counselling should be tailored to help adolescents with low self-esteem. In general, interventions should involve building adolescents' skills in areas in which they are deficient. Teachers and community members can carry out these interventions. Family members and teachers can also prevent or reduce low self-esteem by reducing social comparison cues and offering encouragement.

In the course of this study, more questions about SRB have emerged. Future research should use other data collection methods such as in-depth interviews. To our knowledge, there have been no previous longitudinal studies of sexual risk behaviour in the Malaysian context. Longitudinal studies can help to unravel developmental progressions, identifying which factors come into play earlier and which come later in the development of SRB.

Adolescents in welfare institutions need to be aware of how to protect themselves from the consequences of SRB. Interventions should convey the message that anyone who is or will be sexually active is at risk for contracting sexually transmitted infections and experiencing teenage pregnancy.

\section{Conclusions}

This cross-sectional study shows that SRB among male adolescents is determined predominantly by individual factors such as substance use. For most female adolescents, SRB was linked to both individual and interpersonal factors such as self-esteem and family connectedness. These findings indicate the need for gender-specific interventions that aim to reduce SRB by preventing adolescent substance use, increasing adolescent self-esteem, improving adolescents' life skills, and promoting good parenting skills.

\section{Competing interests}

The authors declare that they have no competing interests.

\section{Authors' contributions}

ND, SCR, MD, NAS and NAA conceived the study. ND, MD and NAS drafted the manuscript. ND and SCR undertook the statistical analysis. All of the authors read and approved the final manuscript.

\section{Acknowledgements}

We would like to thank the Postgraduate Research Fund, University of

Malaya, Kuala Lumpur, Malaysia (Grant Number: PS166/2009B) for supporting

this study. We would also like to acknowledge the Social Welfare

Department of Malaysia, Ministry of Women, Family and Community

Development for contributing to this study. 
This article has been published as part of BMC Public Health Volume 14 Supplement 3, 2014: Proceedings of the International Research Symposium on Population Health 2013. The full contents of the supplement are available online at http://www.biomedcentral.com/bmcpublichealth/ supplements/14/S3. Publication charges for this supplement were funded by the University of Malaya.

\section{Authors' details}

${ }^{1}$ Department of Social and Preventive Medicine, Faculty of Medicine, University of Malaya, 50603, Kuala Lumpur, Malaysia. ${ }^{2}$ Centre for Population Health, Faculty of Medicine, University of Malaya, 50603, Kuala Lumpur, Malaysia. ${ }^{3}$ Institute for Health Behavioural Research, Ministry of Health Malaysia, Jalan Rumah Sakit Bangsar, 50590, Kuala Lumpur, Malaysia.

Published: 24 November 2014

\section{References}

1. Bengel J: Sexual Risk Behaviours. International Encyclopedia of the Socia and Behavioural Sciences 2002, 14012-14018.

2. Blum RW, Mmari KN: Risk and Protective Factors Affecting Adolescent Reproductive Health in Developing Countries. Geneva: World Health Organization; 2005.

3. Voisin DR, DiClemente RJ, Salazar LF, Crosby RA, Yarber WL: Ecological Factors Associated with STD Risk Behaviors among Detained Female Adolescents. Social Work 2006, 51(1):71-79.

4. Mmbaga EJ, Leonard F, Leyna GH: Incidence and Predictors of Adolescent's Early Sexual Debut after Three Decades of HIV Interventions in Tanzania: A Time to Debut Analysis. PLOS ONE 2012, 7(7):1-9.

5. Ntaganira J, Hass $L$, Hosner S, Brown L, Mock NB: Sexual risk behaviours among youth heads of household in Gikongoro, south province of Rwanda. BMC Public Health 2012, 12(225):1-13.

6. Wong ML, Chan RK, Koh D, Tan HH, Lim FS, Bishop G: Premarital Sexual Intercourse Among Adolescents in an Asian Country: Multilevel Ecological Factors. Pediatrics 2009, 124(1):e44-e52.

7. Easy Access to the Census of Juveniles in Residential Placement 19972010. [http://www.ojjdp.gov/ojstatbb/ezacjrp].

8. Statistical Report 2010: Children in Need of Protection and Rehabilitation. [http://www.jkm.gov.my].

9. The health and well-being of incarcerated adolescents. [http://www.racp. edu.au].

10. Romero EG, Teplin LA, McClelland GM, Abram KM, Welty LJ, Washburn JJ: A Longitudinal Study of the Prevalence, Development, and Persistence of HIV/STI Risk Behaviours in Delinquent Youth: Implications for Health Care in the Community. In Crime, HIV and Health: Intersections of Criminal Justice and Public Health Concerns.. New York: Springer;Sanders B, Thomas YF, Deeds BG. 2013:19-62

11. Markham CM, Tortolero SR, Escobar-Chaves SL, Parcel GS, Harrist R, Addy RC: Family connectedness and sexual risk-taking among urban youth attending alternative high schools. Perspectives on sexual and reproductive health 2003, 35(4):174-179.

12. Rosengard C, Stein LAR, Barnett NP, Monti PM, Golembeske C, LebeauCraven R: Co-Occuring Sexual Risk and Substance Use Behaviors Among Incarcerated Adolescents. J Correct Health Care 2006, 12(4):279-287.

13. Mason WA, Zimmerman L, Evans W: Sexual and physical abuse among incarcerated youth: implications for sexual behavior, contraceptive use, and teenage pregnancy. Child Abuse \& Neglect 1998, 22(10):987-995.

14. Castrucci B, Martin S: The association between substance use and risky sexual behaviors among incarcerated adolescents. Matern Child Health $J$ 2002, 6(1):43-47.

15. Hendershot CS, Magnan RE, Bryan AD: Associations of marijuana use and sex-related marijuana expectancies with HIV/STD risk behavior in highrisk adolescents. Psychol Addict Behav 2010, 24(3):404-414.

16. Steinberg J, Boudov M, Kerndt P, Grella C, Kadrnka C: Methamphetamine Use and High Risk Sexual Behaviors among Incarcerated Female Adolescents with a Diagnosed STD. Journal of Urban Health 2011, 88(2):352-364.

17. Baumgartner JN, Geary CW, Tucker H, Wedderburn M: The Influence of Early Sexual Debut and Sexual Violence On Adolescent Pregnancy: A Matched Case-Control Study In Jamaica. International Perspectives on Sexual and Reproductive Health 2009, 35(1):21-28.
18. Forhan SE, Gottlieb SL, Sternberg MR, Xu F, Datta SD, McQuillan GM: Prevalence of Sexually Transmitted Infections among female adolescents aged 14 to 19 in the United States. Pediatrics 2009, 124:1505-1512.

19. Haar K, Bremer V, Houareau C, Meyer T, Desai S, Thamm M, Hamouda O: Risk factors for Chlamydia trachomatis infection in adolescents: results from a representative population-based survey in Germany, 2003-2006. Euro Surveill 2013, 18(34):1-10.

20. Underwood C, Skinner J, Osman N, Schwandt H: Structural determinants of adolescent girls' vulnerability to HIV: views from community members in Botswana, Malawi, and Mozambique. Social Science Medicine 2011, 73(2):343-350.

21. Welfare Institution. [http://www.jkm.gov.my].

22. Mohd Jamil BHY: Validity and Reliability Study of Rosenberg Self-Esteem Scale in Seremban School Children. Malaysian Journal of Psychiatry 2006, 15(2):35-39.

23. Crandal R: The measurement of self-esteem and related constructs. Ann Arbor: ISR 1973.

24. Rosenberg M: Society and the adolescent self-image. Princeton, New Jersey: Princeton University Press; 1965.

25. Wylie RC: The self-concept Lincoln, Nebraska: University of Nebraska Press; 1974.

26. Rew L: Adolescent Health: A Multidisciplinary Approach to Theory, Research, and Intervention. California: Sage Publications; 2005.

27. Marla E, Eisenberg S, Olson RE, Neumark-Sztainer D, Story M, Bearinger LH: Correlations Between Family Meals and Psychosocial Well-being Among Adolescents. Arch Pediatr Adolesc Med 2004, 158:792-796.

28. Li X, Feigelman S, Stanton B: Perceived parental monitoring and health risk behaviors among urban low-income African-American children and adolescents. Journal of Adolescent Health 2000, 27:43-48.

29. Small SA, Kerns D: Unwanted sexual activity among peers during early and middle adolescence: Incidence and risk factors. Journal of Marriage and the Family 1993, 55:941-952.

30. National Institute of Child Health and Human Development: Peer Pressure. United States of America; 2005

31. Bachanas PJ, Morris MK, Sarett-Cuasay EJ, Sirl K, Ries JK, et al: Predictors of Risky Sexual Behavior in African American Adolescent Girls: Implications for Prevention Interventions. Journal of Pediatric Psychology 2002, 27(6):519-530

32. Yi S, Poudel KC, Yasuoka J, Palmer PH, Yi S, Jimba M: Role of risk and protective factors in risky sexual behavior among high school students in Cambodia. BMC Public Health 2010, 10(477):1-8

33. Kassim AW: Juveniles on Remand: Trends and Practices in Malaysia. Resource material series / United Nations Asia and Far East Institute for the Prevention of Crime and the Treatment of Offenders 2006, 68:196-208.

34. Statistic Report 2011: Children in Need of Protection and Rehabilitation. [http://www.jkm.gov.my/content.php?pagename=statistik_2011\&lang=bm].

35. Carlson MJ: Family structure, father involvement, and adolescent behavioural outcomes. Journal of Marriage and Family 2006, 68(1):137-154.

36. Lam T, Stewart S, Ho L: Prevalence and correlates of smoking and sexual activity among Hong Kong adolescents. Journal of Adolescent Health 2001, 29(5):352-358.

37. Pahl K, Brook D, Morojele N, Brook J: Nicotine dependence and problem behaviors among urban South African adolescents. Journal of Behavioural Medicine 2010, 33(2):101-109.

38. Giannakopoulos G, Tzavara C, Dimitrakaki C, Kolaitis G, Rotsika V, Tountas Y: Emotional, behavioural problems and cigarette smoking in adolescence: findings of a Greek cross-sectional study. BMC Public Health 2010, 10(57):1-7.

39. Schofield H-LT, Bierman KL, Heinrichs B, Nix RL, Group C.P.P.R: Predicting Early Sexual Activity with Behavior Problems Exhibited at School Entry and in Early Adolescence. Journal of Abnormal Child Psychology 2008, 36(8):1175-1188

40. Hansen EB, Breivik G: Sensation seeking as a predictor of positive and negative risk behaviour among adolescents. Personality and Individual Differences 2001, 30:627-640.

41. Anteghini M, Fonseca H, Ireland M, Blum RW: Health Risk Behaviors and Associated Risk and Protective Factors Among Brazilian Adolescents in Santos, Brazil. Journal of Adolescent Health 2001, 28:295-302.

42. Morojele NK, Kachieng'a MA: Perceptions of sexual risk behaviours and substance abuse among adolescents in South Africa: A qualitative investigation. AIDS Care 2006, 18(3):215-219. 
43. Stanton B, Li X, Cottrell L, Kaljee L: Early initiation of sex, drug-related risk behaviors, and sensation-seeking among urban, low-income AfricanAmerican adolescents. Journal of the National Medical Association 2001, 93(4):129-38

44. Campbell EK: A Note on Alcohol Consumption and Sexual Behaviour of Youths in Botswana. African Sociological Review 2004, 7(1):146-161.

45. Santelli JS, Robin L, Brener ND, Lowry R: Timing of Alcohol and Other Drug Use And Sexual Risk Behaviors Among Unmarried Adolescents and Young Adults. Family Planning Perspectives 2001, 33(5):200-205.

46. Miller BC, Benson B, Galbraith KA: Family Relationships and Adolescent Pregnancy Risk: A Research Synthesis. Developmental Review 2001, 21:1-38.

47. Kalina O, Geckova AM, Jarcuska P, Orosova O, Dijk JPV, Reijneveld SA: Psychological and behavioral factors associated with sexual risk behavior among Slovak students. BioMed Central 2009, 9(15):1-10.

48. Ethier KA, Kershaw TS, Lewis JB, Milan S, Niccolai LM, Ickovics JR: Selfesteem, emotional distress and sexual behavior among adolescent females: Inter-relationships and temporal effects. Journal of Adolescent Health 2006, 38:268-274.

49. Wild LG, Flisher AJ, Bhana A, Lombard C: Associations among adolescent risk behaviours and self-esteem in six domains. Journal of Child Psychology and Psychiatry 2004, 45(8):1454-1467.

50. Baumeister R: Self-esteem: The puzzle of low self-regard. New York: Plenum; 1993.

51. Pipher M: Reviving Ophelia: Saving the selves of adolescent girls. New York: Ballantine; 1994.

52. Yaacob SN, Juhari R, Talib MA, Uba I: Loneliness, stress, self esteem and depression among Malaysian adolescents. Jurnal Kemanusiaan 2009, 14:85-95.

doi:10.1186/1471-2458-14-S3-S9

Cite this article as: Farid et al:: Predictors of sexual risk behaviour among adolescents from welfare institutions in Malaysia: a cross sectional study. BMC Public Health 2014 14(Suppl 3):S9.

\section{Submit your next manuscript to BioMed Central and take full advantage of:}

- Convenient online submission

- Thorough peer review

- No space constraints or color figure charges

- Immediate publication on acceptance

- Inclusion in PubMed, CAS, Scopus and Google Scholar

- Research which is freely available for redistribution

Submit your manuscript at www.biomedcentral.com/submit
Ciomed Central 